1. DMRD, FCPS

Associate Professor

Department of Radiology

Allied Hospital/

Faisalabad Medical University, Faisalabad.

2. FCPS

Assistant Professor

Department of Radiology

Allied Hospital/

Faisalabad Medical University,

Faisalabad.

3. FCPS

Senior Registrar

DHQ Hospital/

Faisalabad Medical University, Faisalabad.

4. FCPS

Senior Registrar Department of Radiology

DHQ Hospital/

Faisalabad Medical University,

Faisalabad.

Correspondence Address:

Dr. Syed Anjum Mehdi

Associate Professor

Department of Radiology

Allied Hospital/

Faisalabad Medical University

Faisalabad.

dranjumehdi@gmail.com

Article received on:

25/03/2019

Accepted for publication:

$19 / 11 / 2019$

\section{POSITIVE PREDICTIVE VALUE OF BIRADS (BREAST IMAGING REPORTING AND DATA SYSTEM) IV LESIONS IN DETECTION OF CARCINOMA BREAST, USING HISTOPATHOLOGY AS A GOLD STANDARD.}

\begin{abstract}
Syed Anjum Mehdi', Hassan Bukhari², Irfan Shabbir ${ }^{3}$, Sobia Shabbir ${ }^{4}$
ABSTRACT...Objective: To determine the Positive Predictive Value of BIRADS IV lesions in detection of carcinoma breast, using histopathology as a gold standard. Study Design: A Cross-Sectional study. Setting: Department of Radiology Allied Hospital Faisalabad. Period: From 01-09-2015 to 01-03-2016. Material \& Methods: 93 female patients referred to radiology department were included after taking consent. Data were collected on structured proforma. The final diagnosis of the BIRASDS IV lesion seen on mammography has made by consultant. Then patients were sent for biopsy. Mammographic diagnose was then compared with the histopathological diagnose by consultant. The primary performance outcomes of diagnostic mammography like sensitivity, specificity and accuracy were evaluated. Results: The mean age of patients was $45.96 \pm 7.85$ years. There were 19 females had subcategory A, 22 had subcategory $B$ and 52 females had subcategory $C$. The mean size of lump was $3.23 \pm 0.69 \mathrm{~cm}$. The mean duration of symptoms was $3.97 \pm 3.43$ months. On BIRADS IV, malignant lesion detected in $71(76.3 \%)$ females while $22(23.7 \%)$ females had benign lesion. On histopathology, malignant lesions detected in $50(53.8 \%)$ females while $43(46.2 \%)$ females had benign lesion. Findings of BIRADS IV were compared with histopathology and the PPV was $43.7 \%$ and NPV was $13.6 \%$. Conclusion: Through findings of this study, we concluded that in comparison to histopathology, BIRADS IV had PPV of $43.7 \%$ and NPV of $13.6 \%$. In some cases, we can rely on BIRADS-IV and skip interventional method including biopsy for diagnosis of breast lesion.
\end{abstract}

Key words: $\quad$ Breast Lumps, Breast Cancer, BIRADS IV, Histopathology, Mammography.

Article Citation: Mehdi SA, Bukhari H, Shabbir I, Shabbir S. Positive predictive value of BIRADS (Breast imaging reporting and data system) IV lesions in detection of carcinoma breast, using histopathology as a gold standard. Professional Med J 2020; 27(1):172-179. DOI: 10.29309/TPMJ/2020.27.1.4268

\section{INTRODUCTION}

Breast diseases are common misery of the females. About one-fourth of women suffer from breast disease in their life span after adolescence. At least $90 \%$ patients attending a breast clinic will have a benign breast status. ${ }^{1}$ Carcinoma of Breast among women is the most typical malignancy and stands second as the culprit for related deaths. ${ }^{2}$

Among US women more than 180,000 new cases of breast cancer are diagnosed each year and more than 40,000 women die from its fatality. ${ }^{3}$ More recently there has been increase in incidence of breast cancer in developing countries. ${ }^{4}$ In Pakistan breast cancer epidemiology is troublesome to portray due to inadequacy of tumor registry system 4 but it is most often listed malignancy , computing for one third of all cancers occurring in females. ${ }^{5}$

Mammographic reporting, evaluation of the disease and perceptions are based on The Breast Imaging Reporting and Data System (BIRADS) developed by the American College of Radiology. Concerns of diagnostic mammography along with sonographic findings are incorporated in the same report with final judgment division ranging from 1 to 6 according to the degree of lesion suspicion. ${ }^{6}$

The Fourth edition of BI-RADS was published in 2003 Comprising category of sonomammogram and magnetic Resonance imaging as well as sub-categorizing category 4 lesion into (4A, $4 B$ and $4 C) 3$ subdivisions. Suspicious looking lesions falling in BIRAD IV are stratified and they 
require interventional procedures. 4A category of BIRADS IV (needing intervention but low suspicion for malignancy), category 4B (lesions with intermediate suspicion for malignancy) and category 4C (moderate concern but not classic for malignancy). Clinicians are better communicated by the extent of disease process and about the level of involvement for carcinoma. ${ }^{7}$ This subdivision also revitalize pathologists to conscious of benign subcategory $4 \mathrm{C}$ lesions.7 Subcategorizing BI-RADS category 4 lesions are helpful to update the level of concern for carcinoma. Literature review showed positive predictive value of $8.8 \%$ for subcategory $4 \mathrm{~A}$, for subcategory $4 \mathrm{~B}$ it was $18.9 \%$, and $58.3 \%$ was for subcategory $4 \mathrm{C}^{8}$

While screening mammography is highly tricky for the apprehension of clinically veiled breast cancer, most mammographically identified suspicious lesions for which biopsy is recommended will prove to be benign. Other involvements are psychological impact and probable complexity of radiographic interpretation of future mammograms. A latter report in the New York Times portray the high rate of breast biopsies as diagnostic overkill, drastic and valuable. ${ }^{9}$ Fibrocystic disease of the breast stands second to ductal carcinoma in situ(DCIS) according to a study conducted in 2010. ${ }^{10}$

Although Mammogram owns moderate sensitivity (approximately 80\%) and specificity (approximately $85 \%$ ), especially for dense breasts (sensitivity of approximately $60 \%$ ) and less than $1 \mathrm{~cm}$ lesios, et is considered to be the gold standard [1-5]. ${ }^{11}$

Though carries overall limited sensitivity and specificity mammography is capable for early detection of breast cancer and therefore results in decreased mortality. ${ }^{12}$

Although mammographic lesions classified as BIRADS 4 are considered suspicious for carcinoma - by definition - and biopsy (bx) is therefore always recommended, only $20-30 \%$ of such lesions ultimately yield malignancy at biopsy. ${ }^{13}$
BI-RADS classification helps in detection of breast parenchymal changes and its risk of malignancy. It also guided whether biopsy of that change is indicated or not. Histopathological verification is necessary in BI-RADS 4 ( $A, B, C)$, which yields an appropriate indicator of BI-RADS classification accuracy. Therefore, the purpose of this study was to categorize mammographic finding into BI-RADS $4(\mathrm{~A}, \mathrm{~B}, \mathrm{C})$ and correlation with histopathological finding of a breast change. ${ }^{14}$

\section{RATIONALE}

The rationale of this study emphasizes on evaluating the authenticity of BI-RADS category 4 lesions and their malignant outcome using histopathology as a gold standard. On careful literature search very limited data available in our part of society, as breast cancer is leading cause of death my study will be aid in seeking a more reliable guideline and to minimize unnecessary interventions for breast cancer detection.

\section{MATERIAL AND METHODS}

\section{Inclusion Criteria}

Diagnosed case of BIRADS-IV lesions in mammography as described in operational definition irrespective of category were included in the study. Only adult female patients (30-60 years) having family history or palpable Breast lump of size $(1-5 \mathrm{~cm})$ were selected.

\section{Exclusion Criteria}

Unwilling patients, patients with diagnosed breast carcinoma and benign diseases, patients with residual cancer after surgery, chemotherapy and radiotherapy, patients with metastatic deposits in the breast and male patients were excluded from the study.

\section{Data Collection}

All female patients refer to radiology department and fulfilled the inclusion criteria were included in this study. Verbal informed consent was taken for procedure and enrolment for this study. Data was collected on a structured proforma (attached at the end of this synopsis). Detailed history was taken and breast examination was done by consultant radiologist. Mammography 
was performed with Planned Sophie Classic RFH 40822 by mammographic consultant. Standard mediolateral oblique and craniocaudal projections were obtain, additional projections such as coned down compression, magnification, axillary and true lateral views were taken if needed. The mammograms were reported by radiologist experienced more than five years in breast mammography for evaluation of abnormalities like mass with its peculiar characteristics, calcification pattern, asymmetric density, architectural distortion, abnormal axillary nodes. The final diagnosis of BIRADS IV lesion irrespective of category seen on mammography was made by consultant. Then patients were followed till biopsy. Mammographic diagnosis was compared with the histopathological report by consultant. Histopathological report was accessed and findings were noted down along with age and subcategories o BIRADS-IV lesion $(A, B, C)$.

\section{Data Analysis Procedure}

SPSS software package (version 16.0, SPSS) was used for statistical analysis. Continuous variables seen as age, size of lump, and duration of symptoms were presented as mean \& SD. Frequency of qualitative variables seen as BIRADS IV histopathological diagnosis. To assess the diagnostic assessments of as BIRADS IV lesion category positive predictive value and negative predictive value test were calculated. Effect modifier were controlled through stratification of age, duration of symptoms, size of the breast lump and subcategories of BIRADS IV.

\section{RESULTS}

The mean age of patients was $45.96 \pm 7.85$ years. The minimum age of females was 35 years while maximum age of females was 60 years. (Table-l)

There were 31 (33.3\%) females were of age 30 40 years, $38(40.9 \%)$ females were of age 40 50 years, $24(25.8 \%)$ were of age $50-60$ years. (Table-II)

There were 19 females had subcategory A, 22 had subcategory $B$ and 52 females had subcategory C. (Figure-1)
The mean size of lump was $3.23 \pm 0.69 \mathrm{~cm}$. The minimum and maximum size of lump were 2.0 and $5.0 \mathrm{~cm}$. (Table-III)

In this study, 2 (2.2\%) females had lump size $1-2 \mathrm{~cm}, 44(47.3 \%)$ had size $2-3 \mathrm{~cm}, 37$ (39.8\%) had $3-4 \mathrm{~cm}$ lump size while $10(10.8 \%)$ females had $4-5 \mathrm{~cm}$ lump size. (Table-IV)

The mean duration of symptoms was $3.97 \pm 3.43$ months. The minimum duration was 1 month while maximum duration was 14 months. (Table-V)

In this study, $56(60.2 \%)$ females had duration of symptoms of 1-3months, 21 (22.6\%) females had duration of symptoms of 3-6months, 3 (3.2\%) females had duration of symptoms of 6-9months, $10(10.8 \%)$ females had duration of symptoms of $9-12$ months and 3 (3.2\%) females had duration of symptoms of $12-16$ months. (Table-VI)

In this study, 42 females had lesion in right breast while 51 females had lesion in left side. (Figure-2)

On BIRADS IV, malignant lesion detected in 71 (76.3\%) females while 22 (23.7\%) females had benign lesion. (Table-VII)

On histopathology, malignant lesions detected in $50(53.8 \%)$ females while $43(46.2 \%)$ females had benign lesion. (Table-VIII)

Findings of BIRADS IV were compared with histopathology and the PPV was $43.7 \%$ and NPV was $13.6 \%$. (Table-IX)

Data was stratified for age and it was noticed that the PPV and NPV of BIRADS IV were $38.5 \%$ and $40 \%$ in age $30-40 y e a r s, 36 \%$ and $7.7 \%$ in age group $40-50$ years and $60 \%$ and $0 \%$ in age $50-60$ years, respectively. (Table-X)

Data was stratified for subcategory and it was noticed that the PPV and NPV of BIRADS IV were $18.2 \%$ and $0 \%$ for subcategory $A, 26.3 \%$ and $66.7 \%$ for subcategory $B$, and $58.5 \%$ and $9.1 \%$ for subcategory C. (Table-XI) 
Data was stratified for duration of symptoms and it was noticed that the PPV and NPV of BIRADS IV were $43.2 \%$ and $16.7 \%$ for $1-3$ months duration, $42.1 \%$ and $0 \%$ for $3-6$ months, $100 \%$ and $0 \%$ for 6-9months, $50 \%$ and $0 \%$ for $9-12$ months and $0 \%$ and $50 \%$ for $12-16$ months duration. (Table-XII)

Data was stratified for size of lesion and it was noticed that the PPV and NPV of BIRADS IV were $0 \%$ for $1-2 \mathrm{~mm}$ size, $47.2 \%$ and $0 \%$ for $2-3 \mathrm{~mm}$ size, $44.8 \%$ and $25 \%$ for $3-4 \mathrm{~mm}$ size and $20 \%$ and $20 \%$ for $4-5 \mathrm{~mm}$ size of lesion. (Table-XIII)

\begin{tabular}{|l|c|c|c|c|c|}
\hline & $\mathbf{n}$ & Mean & SD & Minimum & Maximum \\
\hline Age (years) & 93 & 45.96 & 7.85 & 35 & 60 \\
\hline
\end{tabular}

Table-I. Descriptive statistics of age of patients.

\begin{tabular}{|l|c|c|}
\hline \multicolumn{1}{|c|}{ Age (yrs) } & Frequency & Percent \\
\hline $30-40$ & 31 & $33.3 \%$ \\
\hline $40-50$ & 38 & $40.9 \%$ \\
\hline $50-60$ & 24 & $25.8 \%$ \\
\hline Total & 93 & $100 \%$ \\
\hline
\end{tabular}

Table-II. Distribution of patients in different age groups.

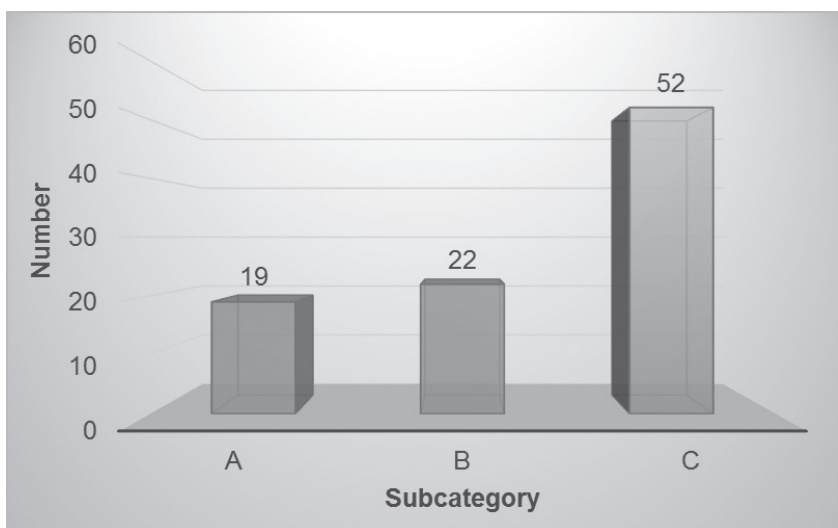

Figure-1. Distribution of subcategory.

\begin{tabular}{|l|l|l|l|l|l|}
\hline Size of lump & 93 & 3.23 & 0.69 & 2.0 & 5.0 \\
\hline
\end{tabular}

Table-III. Descriptive statistics of size of lump.

\begin{tabular}{|c|l|c|c|}
\hline \multicolumn{2}{|c|}{ Size } & Frequency & Percent \\
\hline \multirow{3}{*}{ Size } & $1-2$ & 2 & 2.2 \\
\cline { 2 - 4 } & $2-3$ & 44 & 47.3 \\
\cline { 2 - 4 } & $3-4$ & 37 & 39.8 \\
\cline { 2 - 4 } & $4-5$ & 10 & 10.8 \\
\hline & Total & 93 & 100.0 \\
\hline
\end{tabular}

Table-IV. Distribution of size of lesion (in categories).

\begin{tabular}{|l|c|c|c|c|c|}
\hline & $\mathbf{n}$ & Mean & SD & Minimum & Maximum \\
\hline $\begin{array}{l}\text { Duration } \\
\text { (in month) }\end{array}$ & 93 & 3.97 & 3.43 & 1 & 14 \\
\hline
\end{tabular}

Table-V. Descriptive statistics of duration of lesion.

\begin{tabular}{|l|l|c|c|}
\hline \multicolumn{2}{|c|}{ Duration } & Frequency & Percent \\
\hline \multirow{3}{*}{ Duration } & $1-3$ months & 56 & $60.2 \%$ \\
\hline \multirow{3}{*}{$3-6$ months } & 21 & $22.6 \%$ \\
\hline & 6-9 months & 3 & $3.2 \%$ \\
\hline & $9-12$ months & 10 & $10.8 \%$ \\
\hline & $12-16$ months & 3 & $3.2 \%$ \\
\hline & Total & 93 & $100 . \%$ \\
\hline
\end{tabular}

Table-VI. Descriptive statistics of duration of symptoms.

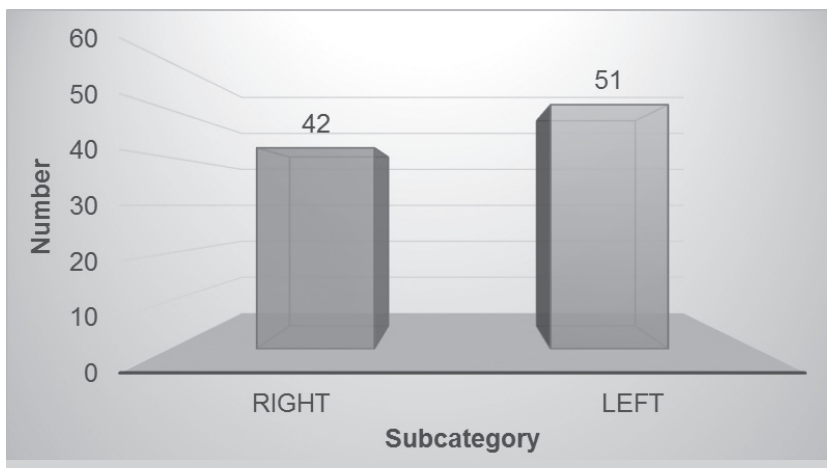

Figure-2. Distribution of side of lesion.

\begin{tabular}{|l|c|c|}
\hline \multicolumn{1}{|c|}{ BIRADS IV } & Frequency & Percent \\
\hline Malignant & 71 & $76.3 \%$ \\
\hline Benign & 22 & $23.7 \%$ \\
\hline Total & 93 & $100 \%$ \\
\hline
\end{tabular}

Table-VII. Distribution of findings of BIRADS IV.

\begin{tabular}{|c|c|c|c|}
\hline & & Frequency & Percent \\
\hline \multirow{3}{*}{ Histopathology } & Malignant & 50 & $53.8 \%$ \\
\hline & Benign & 43 & $46.2 \%$ \\
\hline & Total & 93 & $100 \%$ \\
\hline
\end{tabular}

Table-VIII. Distribution of findings of histopathology.

\begin{tabular}{|l|c|c|c|}
\hline \multirow{2}{*}{ BIRADS IV } & \multicolumn{2}{|c|}{ Histopathology } & Total \\
\hline Malignant & Benign & \\
\hline Benign & 31 & 40 & 71 \\
\hline Total & 19 & 3 & 22 \\
\hline
\end{tabular}

Table-IX. Comparison of BIRADS IV and histopathology.

$\mathrm{PPV}=43.7 \%$

$\mathrm{NPV}=13.6 \%$ 


\begin{tabular}{|c|c|c|c|c|c|c|}
\hline \multirow{2}{*}{ Age } & \multirow{2}{*}{ BIRADS IV } & \multicolumn{2}{|c|}{ Histopathology } & \multirow{2}{*}{ Total } & \multirow{2}{*}{ PPV } & \multirow{2}{*}{ NPV } \\
\hline & & Malignant & Benign & & & \\
\hline \multirow{3}{*}{$30-40$} & Malignant & 10 & 16 & 26 & \multirow{3}{*}{38.5} & \multirow{3}{*}{40} \\
\hline & Benign & 3 & 2 & 5 & & \\
\hline & Total & 13 & 18 & 31 & & \\
\hline \multirow[b]{2}{*}{$40-50$} & Malignant & 9 & 16 & 25 & \multirow[b]{2}{*}{36} & \multirow[b]{2}{*}{7.7} \\
\hline & Benign & 12 & 1 & 13 & & \\
\hline \multirow[t]{2}{*}{$50-60$} & Benign & 4 & 0 & 4 & \multirow[t]{2}{*}{60} & \multirow[t]{2}{*}{0} \\
\hline & Total & 16 & 8 & 24 & & \\
\hline
\end{tabular}

Table-X. Comparison of BIRADS IV and histopathology stratified for age.

\begin{tabular}{|c|c|c|c|c|c|c|}
\hline \multirow{2}{*}{ Subcategory } & \multirow{2}{*}{ BIRADS IV } & \multicolumn{2}{|c|}{ Histopathology } & \multirow{2}{*}{ Total } & \multirow{2}{*}{ PPV } & \multirow{2}{*}{ NPV } \\
\hline & & Malignant & Benign & & & \\
\hline \multirow{3}{*}{$A$} & Malignant & 2 & 9 & 11 & \multirow{3}{*}{18.2} & \multirow{3}{*}{0} \\
\hline & Benign & 8 & 0 & 8 & & \\
\hline & Total & 10 & 9 & 19 & & \\
\hline \multirow[b]{2}{*}{ B } & Malignant & 5 & 14 & 19 & \multirow[b]{2}{*}{26.3} & \multirow[b]{2}{*}{66.7} \\
\hline & Benign & 1 & 2 & 3 & & \\
\hline \multirow[t]{2}{*}{ C } & Benign & 10 & 1 & 11 & \multirow[t]{2}{*}{58.5} & \multirow[t]{2}{*}{9.1} \\
\hline & Total & 34 & 18 & 52 & & \\
\hline
\end{tabular}

Table-XI. Comparison of BIRADS IV and histopathology stratified for subcategory.

\begin{tabular}{|c|c|c|c|c|c|c|}
\hline \multirow{2}{*}{ Duration of Symptoms } & \multirow{2}{*}{ BIRDS IV } & \multicolumn{2}{|c|}{ Histopathology } & \multirow{2}{*}{ Total } & \multirow{2}{*}{ PPV } & \multirow{2}{*}{ NPV } \\
\hline & & Malignant & Benign & & & \\
\hline \multirow{2}{*}{ 1-3 months } & Malignant & 19 & 25 & 44 & \multirow{2}{*}{43.2} & \multirow{2}{*}{16.7} \\
\hline & Benign & 10 & 2 & 12 & & \\
\hline 3-6 months & Benign & 2 & 0 & 2 & 42.1 & 0 \\
\hline 6-9 months & Malignant & 1 & 0 & 1 & 100 & 0 \\
\hline 9-12months & Benign & 4 & 0 & 4 & 50 & 0 \\
\hline \multirow{2}{*}{$12-16$ months } & Malignant & 0 & 1 & 1 & \multirow{2}{*}{0} & \multirow{2}{*}{50} \\
\hline & Benign & 1 & 1 & 2 & & \\
\hline
\end{tabular}

Table-XII. Comparison of BIRADS IV and histopathology stratified for duration of symptoms.

\begin{tabular}{|c|c|c|c|c|c|c|}
\hline \multirow{2}{*}{ Size } & \multirow{2}{*}{ Birds IV } & \multicolumn{2}{|c|}{ Histopathology } & \multirow{2}{*}{ Total } & \multirow{2}{*}{ PPV } & \multirow{2}{*}{ NPV } \\
\hline & & Malignant & Benign & & & \\
\hline \multirow{3}{*}{$1-2 \mathrm{~cm}$} & Malignant & 0 & 1 & 1 & \multirow{3}{*}{0} & \multirow{3}{*}{0} \\
\hline & Benign & 1 & 0 & 1 & & \\
\hline & Total & 1 & 1 & 2 & & \\
\hline \multirow{3}{*}{$2-3 \mathrm{~cm}$} & Malignant & 17 & 19 & 36 & \multirow{3}{*}{47.2} & \multirow{3}{*}{0} \\
\hline & Benign & 8 & 0 & 8 & & \\
\hline & Total & 25 & 19 & 44 & & \\
\hline \multirow{3}{*}{$3-4 \mathrm{~cm}$} & Malignant & 13 & 16 & 29 & \multirow{3}{*}{44.8} & \multirow{3}{*}{25} \\
\hline & Benign & 6 & 2 & 8 & & \\
\hline & Total & 19 & 18 & 37 & & \\
\hline \multirow{3}{*}{$4-5 \mathrm{~cm}$} & Malignant & 1 & 4 & 5 & \multirow{3}{*}{20} & \multirow{3}{*}{20} \\
\hline & Benign & 4 & 1 & 5 & & \\
\hline & Total & 5 & 5 & 10 & & \\
\hline
\end{tabular}




\section{DISCUSSION}

Improvement in sonographic equipment quality has proved a major role in breast imaging and lesions detection. ${ }^{15}$

Detection of mammographically occult masses in women of less than 50 years age has increased by the use of sonomammoram up to $27 \% .^{15,16}$ In 2003 the American College of Radiology developed the first version of BI-RADS US lexicon on account of this increasing use of US, in order to better characterize breast lesions and for their standardized characterization with US, as with mammography. ${ }^{17}$ It was also explained that $\mathrm{BI}$ RADS criteria are insufficient for distinguishing between malignant and benign lesions, and biopsy is mandatory in such cases. ${ }^{18}$

Thus we conducted this study non 93 female with suspicion of breast lesions. The mean age of patients was $45.96 \pm 7.85$ years. In our study, mostly females were of age $40-50$ years $(40.9 \%)$. The mean size of lump was $3.23 \pm 0.69 \mathrm{~cm}$. The mean duration of symptoms was $3.97 \pm 3.43$ months. In this study, 42 females had lesion in right breast while 51 females had lesion in left side.

In our study, we found that there were 19 females had subcategory A, 22 had subcategory B and 52 females had subcategory C. In one study conducted by Sanders, et al., 94 of 191 (49\%) were $4 \mathrm{~A}, 73(38 \%)$ were $4 \mathrm{~B}$, and $24(13 \%)$ were $4 C .{ }^{10}$

In our study, on BIRADS IV, 71 (76.3\%) females had malignant lesion while $22(23.7 \%)$ females had benign lesion. On histopathology, 50 (53.8\%) females malignant lesions while 43 (46.2\%) females had benign lesion. Findings of BIRADS IV were compared with histopathology and the PPV was $43.7 \%$ and NPV was $13.6 \%$.

In a Brazilian study, it was reported that in a comparison of the different imaging modalities with BI-RADS categories in a Brazilian study showed, increased PPV among the modalities for the category 5 (100\% for mammography, and $92.85 \%$ for MRI). Category 3 lesions are MR negative with NPV approaching (100\%), while intermediate PPV exhibited by mammography and sonomammogram (respectively $69.23 \%$ and $70.58 \%)$. And all the three modalities exhibited intermediate PPV for category 4: ultrasound, $50 \%$; mammography, $63 \%$; and MRI, $65.96 \%{ }^{19}$

In our study, for subcategory, the PPV and NPV of BIRADS IV were $18.2 \%$ and $0 \%$ for subcategory A, $26.3 \%$ and $66.7 \%$ for subcategory B, and $58.5 \%$ and $9.1 \%$ for subcategory C. Prado et al., reported that PPV for categories 3, 4 and 5 were, respectively, $7.14 \%, 16.96 \%$ and $82.61 \%{ }^{20}$ In the USA, this value ranges between $15 \%$ and $40 \% .{ }^{21-23}$ Met analysis of the studies have shown gradually increased PPV, for BIARDS category 3 between $0 \% \& 3 \%$, while for category 4 it is between $15 \%$ and $40 \%$, and for category 5 , it ranges between $81 \%$ and $97 \% .{ }^{23-28}$

Wiratkapun et al., reported $21 \%$ overall PPV for BIRADS IV and PPVs for subcategories 4A, 4B and $4 \mathrm{C}$, were $9 \%, 21 \%$ and $57 \%$, respectively. ${ }^{29}$

Another study conducted in South Africa, demonstrated a PPV of $20.9 \%$ for category 4 . And results of this study correlated well with international studies for BIRADS 4 and 5 lesions. Among all the malignancies DCIS accounted for $21.4 \%$ and the current literature agrees with it. Thus it was finalized that inspite of limited sources, outcomes were comparable with those of BIRADS. Considering general categorization of the breast lesions, it should be emphasized that BIRADS permits better assimilation of data, compiling, consistency and clarity in reporting system, as well as accurate data comparison among centers facing limitations similar to this study. ${ }^{30}$

Elverici et al., had reported the PPV of BIRADS 4 lesions in determination of typical signs of malignancy, that were irregular shape (PPV, 66\%), speculated margin (PPV, 80\%) and nonparallel orientation (PPV, 58.9\%). Signs exhibited by benign lesions were oval shape (NPV, 77.1\%), ell defined circumscribed margins (NPV, 67.5\%), parallel orientation (NPV, 70\%), and abrupt interface (NPV, 67.6\%).75 
Constantine et al., found that lesions which showed speculated margins and microlobulation were $100 \%$ malignant, same as our findings. ${ }^{31}$

\section{CONCLUSION}

Through findings of this study, we concluded that in comparison to histopathology, BIRADS IV had PPV of $43.7 \%$ and NPV of $13.6 \%$. In some cases, we can rely on BIRADS-IV and skip interventional method including biopsy for diagnosis of breast lesion.

\section{Copyright@ 19 Nov, 2019.}

\section{REFERENCES}

1. Chaudhary IA, Qureshi SK, Rasul S, Bano A. Pattern of benign breast diseases. J Surg Pak 2003; 8(3):5-7.

2. Jemal A, Murray T, Ward E, Samuels A, Tiwari RC, Ghafoor A, et al. Cancer statistics, 2005. CA: a cancer journal for clinicians 2005; 55(1):10-30.

3. Kopans DB. Breast imaging: Lippincott Williams \& Wilkins; 2007.

4. Shahid R, Ghaffar A, Bhatti AM. Role of grey scale ultrasound in benign and malignant breast lesions. Journal of the College of Physicians and SurgeonsPakistan: JCPSP 2005; 15(4):193-5.

5. Gilani G, Kamal S, Akhter A. A differential study of breast cancer patients in Punjab, Pakistan. JPMA The Journal of the Pakistan Medical Association 2003; $53(10): 478-81$.

6. Balleyguier C, Ayadi S, Van Nguyen K, Vanel D, Dromain C, Sigal R. BIRADS ${ }^{\text {TM }}$ Classification in mammography. European journal of radiology 2007; 61(2):192-4.

7. BURIVONG W, AMORNVITHAYACHARN O. Accuracy of subcategories A, B, C in BI-RADS 4 lesions. by combined mammography and breast ultrasound findings. Journal of Medicine and Medical Sciences 2011; 2(3):728-33.

8. Torres-Tabanera M, Cárdenas-Rebollo J, Villar-Castaño P, Sánchez-Gómez S, Cobo-Soler J, Montoro-Martos E, et al. Analysis of the positive predictive value of the subcategories of BI-RADS $\AA 4$ lesions: Preliminary results in $\mathbf{8 8 0}$ lesions. Radiología (English Edition) 2012; 54(6):520-31.

9. Madrid FF, Maroun M-C, Olivero OA, Long M, Stark A, Grossman LI, et al. Autoantibodies in breast cancer sera are not epiphenomena and may participate in carcinogenesis. BMC cancer 2015; 15(1):1.
10. Sanders MA, Roland L, Sahoo S. Clinical Implications of Subcategorizing BI $\square$ RADS 4 Breast Lesions associated with Microcalcification: A radiologypathology correlation study. The breast journal 2010; 16(1):28-31.

11. Zografos G, Liakou P, Koulocheri D, Liovarou I, Sofras $M$, Hadjiagapis S, et al. Differentiation of BIRADS-4 small breast lesions via Multimodal Ultrasound Tomography. European radiology 2015; 25(2):410-8.

12. Patel BK, Giurescu M, Eversman S, William E, Kosiorek H, Victor $\mathrm{P}$, et al., editors. Can adding contrast-enhanced digital mammography (CEDM) as an adjunct to diagnostic mammography/US help decrease biopsy rates in women with suspicious (BIRADS 4) breast lesions? ASCO Annual Meeting Proceedings; 2015.

13. Gordon MR, Borazanci E, Maki DD, Korn RL. Evaluating high risk BI-RADS 4 mammographic lesions: a pilot trial of textural analysis (TA) as a supplement to digital mammography (DM). Cancer Research 2015; 75(15 Supplement):213-.

14. Dobrosavljević $A$, Rakic S, Nikolić $B$, Janković-Ražnatović $S$, Dragojević-Dikić S, Milošević Z, et al. Diagnostic value of breast ultrasound in mammography BIRADS 0 and clinically indeterminate or suspicious of malignancy breast lesions. Vojnosanitetski pregled 2016; 73(3):239-45.

15. Hong AS, Rosen EL, Soo MS, Baker JA. BI-RADS for sonography: Positive and negative predictive values of sonographic features. American Journal of Roentgenology 2005; 184(4):1260-5.

16. Heinig J, Witteler R, Schmitz R, Kiesel L, Steinhard $\mathrm{J}$. Accuracy of classification of breast ultrasound findings based on criteria used for BI $\square$ RADS. Ultrasound in Obstetrics \& Gynecology 2008; 32(4):5738.

17. American College of Radiology. BI-RADS ultrasound. American College of Radiology, editor. Reston,VA: American College of Radiology; 2003.

18. Elverici E, Barça AN, Aktaş H, Özsoy A, Zengin B, Çavuşoğlu $M$, et al. No palpable BI-RADS 4 breast lesions: sonographic findings and pathology correlation. Diagnostic and Interventional Radiology 2015; $21(3): 189$.

19. Roveda Junior D, Piato S, Oliveira VMd, Rinaldi JF, Ferreira CAP, Fleury EdCF. Predictive values of BIRADS categories 3,4 and 5 in non-palpable breast masses evaluated by mammography, ultrasound and magnetic resonance imaging. Radiologia Brasileira 2007; 40(2):93-8. 
20. Prado GLM, Guerra MTPM. Positive predictive value of Breast Imaging Reporting and Data System (BIRADS $\AA$ ) categories 3,4 and 5. Radiologia Brasileira 2010; 43(3):171-4.

21. Ciatto S, Cataliotti L, Distante V. No palpable lesions detected with mammography: Review of $\mathbf{5 1 2}$ consecutive cases. Radiology 1987; 165(1):99-102.

22. Cyrlak D. Induced costs of low-cost screening mammography. Radiology 1988; 168(3):661-3.

23. Hall FM, Storella JM, Silverstone DZ, Wyshak G. No palpable breast lesions: recommendations for biopsy based on suspicion of carcinoma at mammography. Radiology 1988; 167(2):353-8.

24. Kestelman FP, Souza GAd, Thuler LC, Martins G, Freitas VARd, Canella EdO. Breast Imaging Reporting and Data System-BI-RADS $₫$ : valor preditivo positivo das categorias 3, 4 e 5. Revisão sistemática da literatura. Radiologia brasileira 2007; 40(3):173-7.

25. Raza S, Chikarmane SA, Neilsen SS, Zorn LM, Birdwell RL. BI-RADS 3, 4, and 5 Lesions: Value of US in Management-Follow-up and Outcome 1. Radiology 2008; 248(3):773-81.

26. Orel SG, Kay N, Reynolds C, Sullivan DC. BI-RADS categorization as a predictor of malignancy 1 . Radiology 1999;211(3):845-50.
27. Lacquement MA, Mitchell D, Hollingsworth AB. Positive predictive value of the breast imaging reporting and data system. Journal of the American College of Surgeons 1999; 189(1):34-40.

28. Liberman L, Abramson AF, Squires FB, Glassman J, Morris $E$, Dershaw D. The breast imaging reporting and data system: positive predictive value of mammographic features and final assessment categories. AJR American journal of roentgenology 1998; 171(1):35-40.

29. Wiratkapun C, Bunyapaiboonsri W, Wibulpolprasert B, Lertsithichai $\mathrm{P}$. Biopsy rate and positive predictive value for breast cancer in BI-RADS category 4 breast lesions. Medical journal of the Medical Association of Thailand 2010; 93(7):830.

30. Cupido B, Vawda F, Sabri A, Sikwila C. Evaluation and correlation of mammographically suspicious lesions with histopathology at Addington Hospital, Durban. SAMJ: South African Medical Journal 2013; 103(4):2514.

31. Costantini M, Belli P, lerardi C, Franceschini G, La Torre $\mathrm{G}$, Bonomo L. Solid breast mass characterisation: Use of the sonographic BI-RADS classification. La radiologia medica 2007; 112(6):877-94.

\begin{tabular}{|c|c|c|c|}
\hline \multicolumn{4}{|c|}{ AUTHORSHIP AND CONTRIBUTION DECLARATION } \\
\hline Sr. \# & Author(s) Full Name & Contribution to the paper & Author(s) Signature \\
\hline 1 & Syed Anjum Mehdi & & \\
\hline 2 & & Equal contribution of all & \\
\hline 3 & Irfan Shabbir & authors. & \\
\hline 4 & Sobia Shabbir & & \\
\hline
\end{tabular}

